www.jmscr.igmpublication.org

Impact Factor 5.84

Index Copernicus Value: 83.27

ISSN (e)-2347-176x ISSN (p) 2455-0450

crossref DOI: https://dx.doi.org/10.18535/jmscr/v5i6.34

Journal Of Medical Science And Clinical Research

\title{
Acute Changes in LV Function as Assessed by Strain and Myocardial Performance Index (MPI) in Post Tricuspid Shunts Following Closure
}

\author{
Authors \\ Lakshmi Sadasivan Pillai ${ }^{1}$, Kothandam Sivakumar ${ }^{2}$ \\ ${ }^{1}$ Assistant Professor, Pediatric Cardiology, SAT Hospital, Medical College, Thiruvavananthapuram \\ ${ }^{2}$ HOD, Pediatric Cardiology, Institute of Cardiovascular Diseases, The Madras Medical Mission Chennai, \\ India
}

\begin{abstract}
Background: Hemodynamically significant left to right shunts, once closed, decreases the left ventricular (LV) preload and increases the after load by isolating the low resistance pulmonary circulation from LV outflow circulation. The simultaneous reduction in the LV preload and increase in after load may lead to LV systolic dysfunction. We present our assessment of changes in LV function following closure of significant post tricuspid left to right shunts.

Materials and Methods: This is a prospective study conducted in a tertiary care Pediatric cardiology centre. Patients with post tricuspid shunts who underwent surgery /device closure during the period from march 2016 to November 2016 were included in the study. Patients with Ventricular septald effect VSD) and Patent ductus arteriosus (PDA) with significant left to right shunt as shown by left atrial and left ventricular dilatation on echocardiography were included in the study. Patients with other associated diseases and complex heart diseases were excluded from the study.

Echocardiography for assessment of $L V$ volume and function, strain imaging, and assessment of MPI was done on the day prior to surgery/ device closure. The imaging was repeated one day after intervention and seven days after surgery. All analysis was done in Epic 7 (philips) echocardiography machine by single operator.

Results: A total of 24 patients, 19 with PDA and 5 with VSD were included in the study. Mean age was 16.04 12.08 months and mean body surface area was $0.408 \pm 0.105$. Average size of PDA was $4.58 \pm 1.1 \mathrm{~mm}$ and average size of VSD was $6.2 \pm 1.09 \mathrm{~mm}$. Mean QP/QS was $2.22 \pm 0.743$. All patients with PDA underwent device closure and all patients with VSD had surgical closure except one which was closed with a device. All patients had normal baseline ejection fraction $(E F)$. There was a statistically significant reduction in LV ejection fraction post procedure. 13 i $54.2 \%$ \} Patients had a significant fall in LV ejection fraction post procedure. \{defined as more than or equal to $10 \%$ fall from the baseline or EF post procedure less than 50\%.\}.This included 11 patients $\{57.8 \%\}$ with PDA closed with device and 2\{40\%\} VSD closed surgically. There was no significant difference in pre procedural ejection fraction between the two groups. There was a statistically significant reduction in LVEDVI, longitudinal and circumferential strain of $L V$, LA size and LVEF post procedure.There was no significant change in $L V$ end systolic volume index post procedure. There was a statistically significant increase in LV MPI post procedure.

On comparison of the group with significant reduction in LVEF post procedure with the group with preserved LVEF , we were not able to identify any significant parameters contributing to the reduction in LVEF post procedure.

Conclusion: Acute reduction in LV volume on closure of post tricuspid shunts associates with large left to right shunts and is likely to cause an acute reduction in end diastolic fibre length. Decrease in end diastolic volume can lead to a decrease in ejection fraction by volume unloading. There is also an element of after load mismatch due to removal of shunt which can also account for acute reduction in LV function.
\end{abstract}




\section{Introduction}

Patent ductus arteriosus (PDA) is a congenital heart condition characterized by persistent patency between the proximal left pulmonary artery and the descending aorta, which leads to left to right shunting from the aorta to the pulmonary artery, and a subsequent increase of left ventricular (LV) preload ${ }^{(1,2)}$. Prior to the commercialization of echocardiography, the incidence of PDA was demonstrated to be approximately 1 in 2,000 births, with the exception of complex defects with associated PDA ${ }^{(3,4)}$. Recently however, the incidence of PDA may be as high as 1 in 500 births as asymptomatic PDA is frequently identified by echocardiography ${ }^{(2,3)}$. PDA closure is required in patients with signs of LV volume overload, pulmonary arterial hypertension or symptoms of heart failure

Ventricular septal defects (VSD) are the most common of congenital heart disease (CHD) among infants and children. Its incidence is $20 \%$ of all CHDs .Moderate sized and large VSD causes volume overload of the left atrium and ventricle and left ventricular hypertrophy. Because of the marked volume overload of the left ventricle, congestive heart failure is particularly likely to occur.

Treatment of the majority of PDAs is accomplished by surgical or catheter closure with a complete closure rate of $90-95 \% \quad(3,9-12)$. Percutaneous PDA closure has proved to be safe and effective with short- and long-term results comparable to surgical closure. ${ }^{[5-8]}$. Transcatheter closure of the PDA has evolved over the last 30 years; today, most PDAs are closed in the catheterization laboratory. Little is known, however, of the degree and timing of changes in left ventricular (LV) size and systolic and diastolic function after percutaneous PDA closure. Echocardiography is the most common tool for evaluation of LV systolic and diastolic performance. The measures of systolic function generally used are ejection fraction (EF) and fractional shortening.
Hemodynamically significant PDA leads to a left ventricle (LV) volume overload and remodelling. LV volume overload and compensatory remodelling alters systolic and diastolic function of $\mathrm{LV}$ as in chronic aortic regurgitation and mitral regurgitation ${ }^{\{13-15\}}$. These changes are expected to improve after PDA closure, however some patients develop LV systolic dysfunction. Transient LV dysfunction following PDA closure has previously been reported, although severe complications are rare ${ }^{(16-19)}$.

\section{Myocardial performance index $\{$ MPI}

There are many limitations to the use of classical echocardiographic indexes for the estimation of systolic and diastolic left ventricular (LV) function. The ejection fraction $(\mathrm{EF}$, an index of systolic function) and LV volumes are subject to large errors when the ellipsoid shape of the heart becomes spherical. TeiChuwa devised and published in 1995 an index of myocardial performance (the Tei index) that evaluates the LV systolic and diastolic function in combination. The Tei index has proved to be a reliable method for the evaluation of LV systolic and diastolic performance, with clear advantages over older established indexes and prognostic value in many kinds of heart disease. Tei index is expressed by the formula IVCT+IVRT/ET where (IVCT) isisovolumic contraction time, (ET) the ejection time and (IVRT) isovolumic relaxation time. The myocardial performance index (MPI) has been described as a non-invasive Doppler measurement of ventricular function.

\section{Strain}

Strain is defined as the fractional or percentage change in an object's dimension in comparison to the object's original dimension. ${ }^{[13]}$ A more recent echocardiographic approach to strain analysis is speckle tracking. Speckle tracking is a postprocessing computer algorithm that uses the routine gray scale digital images.

The present study was conducted to evaluate the LV systolic function in children before and after 
closure of PDA and VSD \{both surgical and interventional\} using two-dimensional (2D) echocardiography, Strain imaging and by calculation of myocardial performance index and to identify predictors of the post PDA and VSD closure LV systolic dysfunction

\section{Materials and Methods}

This is a prospective study conducted at a tertiary Pediatric cardiac care centre .Patients with post tricuspid shunts who underwent surgery /device closure from march 2016 to November 2016 were included in the study. Echocardiography for assessment of LV volume and function, strain imaging, and assessment of MPI was done on the day prior to surgery/ device closure. The imaging was repeated one day after intervention and seven days after surgery. All analysis was done in Epic 7 (philips) echocardiography machine by single operator. LV systolic dysfunction was defined as a post closure absolute EF less than $50 \%$ and/ or reduction in LVEF of more than or equal to $10 \%$ from baseline.

Study included patients with VSD and PDA with significant left to right shunt as shown by left atrial and ventricular dilatation on echocardiography. Children with other associated diseases and complex heart diseases were excluded from the study. After obtaining informed consent cardiac catheterisation was done for shunt quantification. Only venous access was used. Angiographic assessment of PDA was performed in standard lateral view for PDA sizing. PDA was closed using ductaloccluder either Amplatzer or Lifetechin most of the cases and in a few patients Amplatzer vascular plug was also used. After device deployment echocardiography assessment was done for device position and descending thoracic aortic and left pulmonary artery velocity. The device was released after excluding significant residual shunt and obstruction in aorta and / or left pulmonary artery.

VSD patients underwent patch closure of VSD except one patient in whom VSD was closed with a PDA device.

Statistical analysis was done with standard SPSS software. Continuous variables were presented as mean \pm SD and compared using two tailed students t- test. Multiple stepwise linear regression analysis was done to identify the determinants of post closure LVEF. P value of less than 0.05 was taken as significant.

\section{Results}

A total of 24 patients were analysed. This included 19 patients with PDA and 5 patients with VSD. Mean age was $16.04 \pm 12.08$ months. Average body surface area was $0.408 \pm 0.105$. Average size of PDA was $4.58 \pm 1.1 \mathrm{~mm}$. Average size of VSD was $6.2 \pm 1.09 \mathrm{~mm}$. Mean QP/QS was $2.22 \pm$ 0.743.All PDA patients underwent device closure and all VSD had surgical closure except one which was closed with a device.

\begin{tabular}{|c|c|c|c|c|c|}
\hline \multirow{3}{*}{$\begin{array}{l}\text { Longitudinal } \\
\text { strain }\end{array}$} & & mean & SD & STD error mean & pvalue \\
\hline & PRE & 24.35 & 1.963 & 0.401 & \multirow{2}{*}{$<0.001$} \\
\hline & POST & 19.1833 & 1.653 & 0.337 & \\
\hline \multirow[t]{2}{*}{ C strain } & PRE & 17.29 & 4.279 & 0.873 & \multirow[t]{2}{*}{$<0.001$} \\
\hline & POST & 14.04 & 2.822 & 0.576 & \\
\hline \multirow[t]{2}{*}{ MPI } & PRE & 0.4067 & 0.088 & 0.018 & \multirow[t]{2}{*}{$<0.001$} \\
\hline & POST & 0.5079 & 0.012 & 0.022 & \\
\hline \multirow{2}{*}{ EDVI } & PRE & 79.98 & 22.1 & 4.51 & \multirow{2}{*}{$<0.001$} \\
\hline & POST & 60.51 & 19.8 & 4.05 & \\
\hline \multirow[t]{2}{*}{ ESVI } & PRE & 32.99 & 12.85 & 2.67 & \multirow[t]{2}{*}{0.973} \\
\hline & POST & 32.93 & 12.01 & 2.51 & \\
\hline \multirow[t]{2}{*}{ LA SIZE } & PRE & 3.7 & 4.94 & 1.05 & \multirow[t]{2}{*}{$<0.001$} \\
\hline & POST & 3.15 & 4.18 & 0.89 & \\
\hline \multirow[t]{2}{*}{ LV EF } & PRE & 71.5 & 6.73 & 1.40 & $<0.001$ \\
\hline & POST & 61.6 & 9.59 & 2.001 & \\
\hline
\end{tabular}


On analysing the data there was a significant reduction in LV longitudinal strain and circumferential strain post procedure. There was a significant increase in MPI values post procedure. There was a statistically significant reduction in LV end diastolic volume index and mean LA size post procedure with no significant reduction in LV endsystolic volume index post procedure. All patients had normal baseline ejection fraction. There was a statistically significant reduction in LV ejection fraction post procedure.13 $\{54.2 \%\}$ Patients had a significant fall in LV ejection fraction post procedure. $\{$ defined as more than or equal to $10 \%$ fall from the baseline or EF post procedure less than 50\%.\}.This included 11 patients $\{57.8 \%\}$ with PDA closed with device and $2\{40 \%\}$ VSD closed surgically.

Comparison was done between group with a significant fall in ejection fraction and group without a significant fall in ejection fraction to look for any factors which can predict development of LV dysfunction post closure of post tricuspid shunts.

\begin{tabular}{|c|c|c|c|c|c|c|}
\hline & Group & $\mathrm{N}$ & Mean & SD & Std error & $\mathrm{P}$ value \\
\hline \multirow[t]{2}{*}{ AGE } & Fall in EF & 13 & 16.4 & 11.8 & 3.3 & \multirow[t]{2}{*}{0.897} \\
\hline & No fall in EF & 11 & 15.7 & 12.8 & 3.9 & \\
\hline \multirow[b]{2}{*}{ BSA } & Fall in $\mathrm{EF}$ & 13 & 0.433 & 0.107 & 0.0297 & \multirow[t]{2}{*}{0.201} \\
\hline & No fall in EF & 11 & 0.377 & 0.099 & 0.0301 & \\
\hline \multirow[t]{2}{*}{ Longitudinal strain pre procedure } & Fall in EF & 13 & 24.21 & 2.149 & 0.596 & \multirow[t]{2}{*}{0.71} \\
\hline & No fall in EF & 11 & 24.51 & 1.806 & 0.544 & \\
\hline \multirow{2}{*}{$\begin{array}{l}\text { Circumferential strain } \\
\text { procedure }\end{array}$} & Fall in EF & 13 & 17.28 & 4.35 & 1.207 & \multirow[t]{2}{*}{0.97} \\
\hline & No fall in EF & 11 & 17.35 & 4.45 & 1.341 & \\
\hline \multirow[t]{2}{*}{ Myocardial performance index } & Fall in EF & 13 & 0.434 & 0.107 & 0.029 & \multirow[t]{2}{*}{0.1} \\
\hline & No fall in EF & 11 & 0.375 & 0.044 & 0.013 & \\
\hline \multirow[t]{2}{*}{$\mathrm{QP} / \mathrm{QS}$} & Fall in EF & 13 & 2.05 & 0.629 & 0.182 & \multirow[t]{2}{*}{0.28} \\
\hline & No fall in EF & 11 & 2.4 & 0.856 & 0.271 & \\
\hline \multirow{2}{*}{$\begin{array}{l}\text { End diastolic volume index of } \\
\text { LV }\end{array}$} & Fall in EF & 13 & 84.56 & 25.85 & 7.17 & \multirow[t]{2}{*}{0.28} \\
\hline & No fall in EF & 11 & 74.57 & 16.23 & 4.89 & \\
\hline \multirow[t]{2}{*}{ LVejection fraction pre procedure } & Fall in EF & 13 & 73.3 & 7.23 & 2.008 & \multirow[t]{2}{*}{0.409} \\
\hline & No fall in EF & 11 & 69.2 & 5.50 & 1.741 & \\
\hline
\end{tabular}

On comparison of the group with significant reduction in LVEF post procedure with the group with preserved LVEF, we were not able to identify any significant parameters contributing to the reduction in LVEF post procedure.

\section{Discussion}

Chronic volume overload causes LV hypertrophy and is expected to have alteration in cardiac filling and contractile function ${ }^{\{13-15\}}$. Hemodynamically significant left to right shunts, once closed, decreases the LV preload and increases the afterload by isolating the low resistance pulmonary circulation from LV outflow circulation. The simultaneous reduction in the LV preload and increase in after load may lead to LV systolic dysfunction. Sudden reduction in preload and simultaneous relative increase in after load leads to after load mismatch. Sudden changes in loading conditions, pre-existing LV volume overload and chronic compensation by Frank Starling mechanism explains immediate post closure LV systolic dysfunction. The assessment of LV systolic function by $\mathrm{EF}$ is load dependent, however, the reduction of $\geq 10 \%$ and/or absolute LVEF of less than $50 \%$ is unusual and was considered to reflect LV systolic dysfunction. Similar LV systolic dysfunction has been reported in the post operative period of mitral regurgitation surgeries $\{15,20,21\}$.

There are only very few studies assessing LV strain pre and post closure of left to right shunts. One study assessed LV longitudinal strain pre and post PDA ligation in preterm babies. Global and segmental longitudinal strain measures reduced significantly early after PDA closure $(P<0.05)$ but it improved remarkably in the subsequent month $^{\{20\}}$ 
Myocardial performance index in assessment of LV function in post closure of post tricuspid shunts is also not extensively studied. One study has assessed MPI in post operative VSD and found that MPI is a useful index for measurement of the left and right ventricular function. It correlates significantly with the ejection fraction, fractional shortening, VSD size, and the left ventricular size. The right and left ventricular MPI values are significantly elevated immediately post-closure of the VSD, and over a one month period they normalize to be comparable with the values of the control group. The RV preoperative MPI and the immediate postoperative MPI also significantly correlate with the postoperative course of the surgery and are strongly correlated with the duration of ICU stay, the duration of ventilation and the duration of inotropic use ${ }^{\{21\}}$.

Our results are also similar to the above studies in that LV strain showed a significant reduction immediately after closure of the post tricuspid shunts. There was also a significant increase in myocardial performance index in the immediate post closure period. We have not done a follow up evaluation in these patients.

\section{Limitations of study}

Major limitation was the small sample size which limited its power especially in subgroup analysis. Another limitation is that follow up evaluation of these patients were not done to assess for normalisation of the parameters on follow up. LV diastolic function was also not evaluated in these patients.

\section{Conclusions}

Closure of post tricuspid shunts are associated with LV systolic dysfunction in the immediate post closure period.

\section{References}

1. Daniel B: Congenital heart disease: Patent ductus arteriosus. In: Nelson Textbook of Pediatrics. Kliegman RM, Stanton BF, St. Geme JW, Schor NF and Behrman RE (eds). 19th edition. Elsevier Saunders, Philadelphia, PA, pp 1559-1560, 2011.

2. Lloyd TR and Beekman RH III: Clinically silent patent ductus arteriosus. Am Heart J 127: 1664-1665, 1994.

3. Schneider DJ and Moore JW: Patent ductus arteriosus. Circulation 114: 1873-1882, 2006.

4. Mitchell SC, Korones SB and Berendes HW: Congenital heart disease in 56,109 births: Incidence and natural history. Circulation 43: 323-332, 19711. 5.Masura J, Tittel P, Gavora P, Podnar T. Long term outcome of transcatheter patent ductus arteriosus closure using Amplatzer duct occluders. Am Heart J. 2006;151:755.e710. [PubMed]

5. Masura J, Walsh KP, Thanopoulous B, Chan C, Bass J, Goussous Y, et al. Catheter closure of moderate to large sized patent ductus arteriosus using the new Amplatzer duct occluder: Immediate and short term results. J Am CollCardiol. 1998;31:878-82. [PubMed]

6. Bilkis AA, Alwi M, Hasri S, Haifa AL, Geetha K, Rehman MA, et al. The Amplatzer duct occluder: Experience in 209 patients. J Am CollCardiol. 2001;37:258-61. [PubMed]

7. Faella HJ, Hizazi ZM. Closure of the patent ductus arteriosus with the Amplatzer PDA device: Immediate results of the international clinical trial. Catheter Cardiovasc Interv. 2000;51:50-4. [PubMed]

8. Rao PS and Kern MJ (eds): Summary and comparison of patent ductus arteriosus closure methods. In: Catheter Based devices for the Treatment of NonCoronary Cardiovascular Disease in Adults and Children. Philadelphia, PA, Lippincott, Williams, and Wilkins, pp 219228, 2003.

9. Galal MO, Amin M, Hussein A, Kouatli A, Al-Ata J and Jamjoom A: Left 
ventricular dysfunction after closure of large patent ductus arteriosus. Asian Cardiovasc Thorac Ann 13: 24-29, 2005.

10. Tilahun B and Tefera E: Transient left ventricular systolic dysfunction following surgical closure of large patent ductus arteriosus among children and adolescents operated at the cardiac centre, Ethiopia. J Cardiothorac Surg 8: 139, 2013.

11. Kim YH, Choi HJ, Cho Y, Lee SB and Hyun MC: Transient left ventricular dysfunction after percutaneous patent ductus arteriosus closure in children. Korean Circ J 38: 596-600, 2008.

12. Bonow RO, Lakatos E, Maron BJ, Epstein SE. Serial long-term assessment of the natural history of asymptomatic patients with chronic aortic regurgitation and normal left ventricular systolic function. Circulation. 1991;84:1625-35. [PubMed]

13. Enriquez-Sarano M, Avierinos JF, Messika-Zeitoun D, Detaint D, Capps M, Nkomo V, et al. Quantitative determinants of the outcome of asymptomatic mitral regurgitation. N Engl J Med. 2005;352:875-83. [PubMed]

14. Enriquez-Sarano M, Tajik AJ, Schaff HV, Orszulak TA, McGoon MD, Bailey KR, et al. Echocardiographic prediction of left ventricular function after correction of mitral regurgitation: Results and clinical implications. J Am CollCardiol. 1994;24:1536-43. [PubMed].

15. Galal MO, Amin M, Hussein A, Kouatli A, Al-Ata J and Jamjoom A: Left ventricular dysfunction after closure of large patent ductus arteriosus. Asian Cardiovasc Thorac Ann 13: 24-29, 2005.

16. Tilahun B and Tefera E: Transient left ventricular systolic dysfunction following surgical closure of large patent ductus arteriosus among children and adolescents operated at the cardiac centre, Ethiopia. J Cardiothorac Surg 8: 139, 2013.
17. Kim YH, Choi HJ, Cho Y, Lee SB and Hyun MC: Transient left ventricular dysfunction after percutaneous patent ductus arteriosus closure in children. Korean Circ J 38: 596-600, 2008.

18. Jeong YH, Yun TJ, Song JM, Park JJ, Seo DM, Koh JK, Lee SW, Kim MJ, Kang DH and Song JK: Left ventricular remodeling and change of systolic function after closure of patent ductus arteriosus in adults: Device and surgical closure. Am Heart J 154: 436-440, 2007.

19. Evaluation of Left Ventricular Function by Tissue Doppler and Speckle-Derived Strain Rate Echocardiography after Percutaneous Ductus Closure Hamid Amoogzar, Ali Mohammad Shakiba,Dorna Derakhshan, Gholamhossein Ajami, Sirous Cheriki, Mohammad Borzouee, Mohammad Reza Edraki, ima Mehdizadegan.

20. Myocardial performance index after surgical correction of ventricular septal defects Yasser Baghdady, Yasser Kamel, and Waleed Amar 